\title{
0832 SUICIDE REGISTRATION PROCEDURES AND PRACTICES IN EUROPE
}

P Varnik, M Sisask* , A Vrnik, Z Laido, U Maise, A Ibelshuser, C Van Audenhove, A Reynders, R D Kocalevent, M Kopp, A Dosa, E Arensman, C Coffey, C M Van der Feltz-Cornelis, R Gusmo, U Hegerl Correspondence: National Suicide Research Foundation, 1 Perrott Avenue, College Road, Cork, n/a, Ireland

10.1136/ip.2010.029215.832

Suicide is an important primary outcome measure for evaluating the effectiveness of intervention programmes. The aim of the current study was to describe and compare suicideregistration procedures in eight European countries, pinpoint potential deficiencies and provide recommendations on how best to improve the quality of suicide registration in the EU. Qualitative data on suicide registration were collected within the OSPI-Europe project from country experts using a structured questionnaire. Suicide registration was based on the medico-legal system in six countries and the coronial system in two. Differences not only between, but also within these two systems emerged. In every country, the process starts after the fact of death has been ascertained by a physician and any suspicion of injury death has arisen. It ends with registration of the death in the national mortality statistics. Between these stages, several elements that are crucial to the consistency of suicide registration were identified: the professional background and co-operation among the authorities involved, performance of the legal inquiry and forensic autopsy, certification and final decision-making, and the coding and registry system. A model 


\section{IP Safety 2010 abstracts}

for recording suicides with maximum accuracy should include: (1) a comprehensive, accurate and time-limited legal inquiry; (2) obligatory forensic autopsy in all cases of injury death; (3) reciprocal and accurate communication among the authorities involved; (4) electronic data transmission; (5) final decisionmakers access to comprehensive information and (6) specially trained coders entitled to obtain additional information from the legal authorities and the certifiers. 